\title{
A Saúde Coletiva no epicentro da pandemia de COVID-19 no Sistema Único de Saúde
}

\author{
Collective Health at the epicenter of the COVID-19 pandemic in the Unified Health System \\ Salud Colectiva en el epicentro de la pandemia Covid-19 en el Sistema Unificado de Salud
}

\begin{abstract}
RESUMO
Objetivo: refletir sobre os desafios atinentes à Saúde Coletiva no enfrentamento da pandemia de COVID-19 no âmbito do Sistema Único de Saúde (SUS). Método: Ensaio teórico, sustentado por uma revisão narrativa conduzida na MEDLINE, LILACS e SciELO nos idiomas inglês, espanhol e português, em julho de 2020, acrescida da análise crítica do autor. Resultados: No contexto da pandemia do novo coronavírus, é premente a articulação dos pilares fundantes da Saúde Coletiva, como a Epidemiologia, a Administração e Gestão e as Ciências Sociais para efetividade da resposta à COVID-19 no SUS. Ressalta-se que, no contexto sanitário atual, as perspectivas de consolidação do SUS, passa pelo fortalecimento da consciência de cidadania e responsabilidade social, pelo aumento da mobilização dos movimentos e organizações sociais em defesa do direito à saúde, pela conquista da adesão da maioria dos profissionais de saúde ao ideário de SUS e pelo maior comprometimento do Estado e dos dirigentes públicos com a efetivação dos seus princípios e diretrizes. Conclusão: Espera-se que a pandemia da COVID-19 sirva de exemplo para a repolitização da sociedade em defesa do SUS enquanto Sistema Universal de Saúde.
\end{abstract}

DESCRITORES: COVID-19; Saúde Coletiva; Sistema Único de Saúde; Enfermagem em Saúde Pública.

\section{ABSTRACT}

Objective: To reflect on the challenges pertaining to Collective Health in facing the COVID-19 pandemic into the Unified Health System (SUS). Method: Theoretical essay, supported by a narrative review conducted at MEDLINE, LILACS and SciELO in English, Spanish and Portuguese, in July 2020, plus the author's critical analysis. Results: In the COVID-19 pandemic context, the articulation of the pivotal pillars of Collective Health is urgent, such as, Epidemiology, Administration and Management, and Social Sciences for the effective response to COVID-19 in the SUS. It is noteworthy that, in the current health context, the perspectives for consolidating the SUS include strengthening the awareness of citizenship and social responsibility, increasing the mobilization of social movements and organizations in defense of the right to health, winning over the adhesion of the majority from health professionals to the conception of SUS and the greater commitment of the State and public sector leaders to the implementation of its principles and guidelines. Conclusion: It's expected that the COVID-19 pandemic is expected to serve as an example for the re-politicization of society in defense of SUS as a Universal Health System.

DESCRIPTORS: COVID-19; Collective Health; Unified Health System; Public Health Nursing.

\section{RESUMEN}

Objetivo: reflexionar sobre los desafíos relacionados con la Salud Colectiva para enfrentar la pandemia de COVID-19 en el Sistema Único de Salud (SUS). Método: Ensayo teórico, respaldado por una revisión narrativa realizada en MEDLINE, LILACS y SciELO en inglés, español y portugués, en julio de 2020, más el análisis crítico del autor. Resultados: En el contexto de la pandemia de COVID-19, la articulación de los pilares fundamentales de la Salud Colectiva es urgente, como Epidemiología, Administración y Gestión, y Ciencias Sociales para la respuesta efectiva a COVID-19 en el SUS. Es de destacar que, en el contexto actual de salud, las perspectivas para consolidar el SUS incluyen fortalecer la conciencia de ciudadanía y responsabilidad social, aumentar la movilización de movimientos y organizaciones sociales en defensa del derecho a la salud, ganarse la adhesión de la mayoría desde profesionales de la salud hasta la concepción del SUS y el mayor compromiso de los líderes estatales y del sector público con la implementación de sus principios y directrices. Conclusión: Se espera que la pandemia de COVID-19 sirva de ejemplo para la repolitización de la sociedad en defensa del SUS como sistema universal de salud.

DESCRIPTORES: COVID-19; Salud Colectiva; Sistema Único de Salud; Enfermería en Salud Pública.

RECEBIDO EM: 30/07/2020 APROVADO EM: 13/08/2020 


\section{Luís Carlos Lopes-Júnior}

Enfermeiro. Doutor em Ciências pela Universidade de São Paulo (USP). Professor Adjunto do Departamento de Enfermagem, Centro de Ciências da Saúde, Universidade Federal do Espírito Santo - UFES. Área: Saúde Coletiva. Vitória, Espírito Santo, Brasil. ORCID: 0000-0002-2424-6510

\section{INTRODUÇÃO}

D oenças infecciosas emergentes e reemergentes são constantes desafios para a Saúde Coletiva global. Recentes casos de pneumonia ocorridos em Wuhan, China, levaram à descoberta de um novo tipo de Coronavírus (2019-nCoV) - um RNA vírus envelopado, comumente encontrados em humanos, outros mamíferos e aves, capazes de causar doenças respiratórias, entéricas, hepáticas e neurológicas ${ }^{(1)}$. Existem pelo menos seis espécies de coronavírus conhecidas que causam doenças em humanos. Quatro dessas (229E, OC43, NL63 e HKU 1) causam sintomas comuns de gripe em pessoas imunocompetentes, e duas espécies, o coronavírus da Síndrome Respiratória Aguda Grave (SARS-CoV) e o coronavírus da Síndrome Respiratória do Oriente Médio (MERS-CoV) causam doença respiratória grave com taxas elevadas de mortalidade ${ }^{(2)}$. Quanto às características epidemiológicas e clínicas dos casos confirmados de 2019$\mathrm{nCoV}$, na China, uma coorte retrospectiva de 41 pacientes (média de idade de 49 anos, com predominância do sexo masculino) demonstrou que $66 \%$ dos pacientes tiveram contato direto com um grande mercado de frutos do mar e animais. Os sinais e sintomas do 2019$\mathrm{nCoV}$ mais prevalentes e de relevância clínico-epidemiológica foram: febre $(98 \%)$ e tosse seca $(76 \%)^{(3)}$.

Embora a COVID-19 cursa com letalidade baixa em torno de $3 \%$, a transmissibilidade se apresenta alta1, sendo as secreções respiratórias o principal meio de propagação do novo coronavírus $^{2}$. Estudo com base nas observações de infecções pelo novo coronavírus na China, utilizando-se de um modelos de dinâmica metapopulacional em rede e inferência bayesiana para inferir características epidemiológicas associadas a COVID-19, estimou que $86 \%$ de todas as infecções não foram documentadas (IC95\%=82\% -90\%) antes das restrições de viagem. Os achados dessa pesquisa apontaram que a taxa de transmissão de infecções não documentadas por pessoa, foi de $55 \%$ das infecções documentadas ( $46 \%$ a $62 \%)$. No entanto, devido ao seu maior número, as infecções não documentadas foram a fonte de infecção para $79 \%$ dos casos documentados $^{(4)}$. O novo coronavírus já está circulando em 213 países e territórios em todo o mundo, com 17.319.650 infectados e 672.760 mortes registradas em 30 de julho de $2020^{(5)}$.

No Brasil, o primeiro caso de COVID-19 foi confirmado em 26 de fevereiro de 2020, indivíduo do sexo masculino, residente na cidade de São Paulo, que haviam regressado de viagem à Itália. Já no início de janeiro, mediante o surto do novo coronavírus a Secretaria de Vigilância em Saúde do Ministério da Saúde (SVS/MS) acionou os Pontos Focais Nacionais do Regulamento Sanitário Internacional da Organização Mundial da Saúde (OMS). Em 30 de janeiro de 2020, foi publicado o Decreto $\mathrm{n}^{\circ}$ 10.211, que reativa o Grupo Executivo Interministerial de Emergência em Saúde Pública de Importância Nacional e Internacional ${ }^{(6)}$, coordenado pelo $\mathrm{Mi}$ nistério da Saúde, e composto por representantes da Casa Civil; e de diversos Ministérios (Justiça e Segurança Pública; Defesa; etc.) e Agência Nacional de Vigilância Sanitária (Anvisa), cuja atribuição principal reside em articulação de medidas de preparação e de enfrentamento às emergências em Saúde Pública no âmbito nacional e internacional ${ }^{(7)}$.

Após a OMS declarar a COVID-19 como pandemia em 11 de março de $2020^{(8)}$, a propagação do novo coronavírus, tem sido o foco da atenção de cien- tistas, governantes, agências sanitárias, e populações ${ }^{(9)}$. No Brasil, já foram registrados oficialmente 2.566 .765 pessoas infectadas em todos os estados brasileiros, com pelo menos 90.383 mortes confirmadas pelo Ministério da Saúde (MS) em 30 de julho de $2020^{(5)}$.

A comunidade científica mundial vem se mobilizando em tempo record para disseminação de conhecimentos

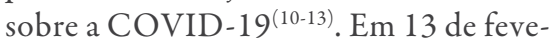
reiro de 2020, já havia sido adicionado o vocabulário COVID-19 aos MeSH terms como descritor de assunto indexado na MEDLINE definido como "A viral disorder characterized by high fever; cough; dyspnea; renal dysfunction and other symptoms of a viral pneumonia. A coronavirus SARS-CoV-2 in the genus betacoronavirus is the suspected agent”. Desde as primeiras publicações científicas sobre a COVID-19 ${ }^{(1,9)}$ até o momento (30/7/2020) o MesH Term “COVID-19" já era citado em 36.228 publicações no portal PubMed, incluindo análises descritivas dos primeiros casos, análises de sequências genômicas, análises epidemiológicas, modelos matemáticos e estatísticos para monitorar o novo coronavírus e definir estratégias de ação, além de desfechos clínicos, e a busca desenfreada para o tratamento do novo coronavírus. Nesse contexto, o presente artigo objetiva refletir sobre os desafios atinentes à Saúde Coletiva no enfrentamento da pandemia de COVID-19 no âmbito do Sistema Único de Saúde (SUS).

\section{METODOLOGIA}

Trata-se de um ensaio teórico, cuja fundamentação baseia-se na formulação discursiva acerca da temática, sustentado na literatura científica nacional e internacional e análise crítica dos autor. Para tanto, realizou-se uma re- 
visão narrativa ${ }^{(14)}$ cuja busca de artigos ocorreu em julho de 2020 na Medical Literature Analysis and Retrieval System Online (MEDLINE) via PubMed, na Literatura Latino-americana e do Caribe em Ciências da Saúde (LILACS) e na Scientific Electronic Library Online (SciELO). Os descritores utilizados na estratégia de busca foram: "COVID-19", SARS-CoV2, Saúde Coletiva, Saúde Pública, Sistema Único de Saúde e Brasil. Foram incluídos estudos primários publicados em inglês, espanhol ou português, de qualquer delineamento bem como a literatura cinzenta (capítulos de livros, revisões, editoriais e guidelines de agências sanitárias de saúde nacional e internacionais), os quais foram posteriormente, submetidos ao Método de Leitura Científica, seguindo os seguintes passos: visão sincrética do texto; visão analítica; visão sintética ou leitura interpretativa ${ }^{(15)}$.

Ressalta-se que a revisão narrativa é constituída por uma análise ampla da literatura, sem estabelecer uma metodologia rigorosa e replicável em nível de reprodução de dados e respostas quantitativas para questões específicas ${ }^{(14)}$. Tal abordagem possibilitou a construção do presente ensaio teórico que consiste na apresentação lógico-reflexiva a partir da literatura científica, com ênfase na argumentação e interpretação do leitor ${ }^{(15)}$. Com base na construção teórica sobre o pensar reflexivo, ${ }^{(16)}$ foi abordado alguns desafios atinentes à Saúde Coletiva no enfrentamento da pandemia de COVID-19 no âmbito do SUS.

\section{RESULTADOS E DISCUSSÃO}

\section{Desafios atinentes à Saúde Coleti- va no enfrentamento da pandemia de COVID-19 no âmbito do Sistema Único de Saúde}

A Saúde Coletiva é definida como um campo interdisciplinar de produção de conhecimentos voltados para a compreensão da saúde, a explicação de seus determinantes sociais, bem como o âmbito de práticas direcionadas prioritariamente para sua promoção, além de voltadas para a prevenção e o cuidado a agravos e doenças, tomando por objeto não apenas os indivíduos, mas, sobretudo, os grupos sociais, portanto, a coletividade ${ }^{(17)}$.

No Brasil, a Saúde Coletiva consolidou-se como espaço multiprofissional (que reúne diversas profissões) e interdisciplinar (que exige a integração de saberes de diferentes disciplinas). Sua evolução tem sido na direção de um campo $^{(18)}$, o qual corresponde a um microcosmo social relativamente autônomo, com objeto específico - a saúde no âmbito dos grupos e classes sociais e com práticas também singulares, voltadas para análise de situações de saúde que incorpora o conhecimento produzido sobre os determinantes sociais do processo saúde-doença-cuidado, a formulação de políticas e a gestão de processos voltados para o controle desses problemas no nível individual e coletivo ${ }^{(19-20)}$. A referência explícita ao conceito Bourdieusiano de campo científico da Saúde Coletiva traz à tona a existência de três pilares disciplinares para sua sustentação: i) Epidemiologia; ii) Planificação e Gestão; e iii) Ciências Sociais ${ }^{(19-20)}$.

No contexto da pandemia da COVID-19, é premente a articulação dos pilares fundantes da Saúde Coletiva para a efetividade da resposta à pandemia no SUS. Por exemplo, no que diz respeito à Epidemiologia, o processamento de dados, o compartilhamento e análise de dados epidemiológicos no Brasil ainda enfrentam desafios apesar dos avanços nas políticas de transparência e o investimento nos últimos anos em sistemas de acompanhamento em tempo real de situação de alerta. A infraestrutura heterogênea que o sistema de Vigilância em Saúde tem, transpõe-se em um desafio importante, uma vez que, a qualidade da informação depende primordialmente da redução do "atrito" à entrada dos dados no sistema. Além disso, outro entrave diz respeito a falta de integração entre diferentes sistemas de informação existentes, impossibilitando a integração de informações de diferentes fontes ${ }^{(10)}$.

Ademais, a frequente emergência de novos agravos exige uma reestruturação na forma como doenças são notificadas no país ${ }^{(21)}$. Considerando a atual era de alta mobilidade global é premente que o MS desenvolva uma infraestrutura integrada de dados à altura da velocidade de propagação das doenças. Há de se considerar um sistema flexível, sobretudo, transparente o suficiente para permitir a entrada de novos agravos, mas sem perder a estrutura existente. Canais rápidos e, sobretudo, transparentes, de notificação e visualização da pandemia pela COVID-19, é essencial para ações estratégicas bem sucedidas ${ }^{(10)}$.

No tocante à Planificação/Administração e Gestão, o SUS se defronta com um problema ainda estrutural da Administração Pública no Brasil, pouco considerado nas análises, que lhe compromete a racionalidade e desempenho. Apesar de se reconhecer o caráter de inovação que o SUS representou na conformação da reforma do Estado brasileiro ainda predomina no cotidiano de gestão dos serviços e do sistema, nos vários âmbitos e dimensões, uma defasagem ante as exigências de racionalidade, continuidade e integração funcional para alcance de resultados. Descompasso resultante da lógica da gestão pública ainda marcada pela descontinuidade, pela fragmentação e desarticulação, orientada por objetivos de curto prazo, em função dos ciclos eleitorais, burocratizada, e em geral operando com baixa eficiência e eficácia e pouca efetividade, em decorrência da tradição patrimonialista e da permeabilidade do Estado aos interesses partidários ou de grupos privados, prevalentes no país ${ }^{(22)}$. Nesse contexto, o planejamento e a programação de coordenação de redes, sistemas e ações integradas não cumprem seu papel de orientar a busca de resultados sanitários para a coletividade.

No âmbito das Ciências Sociais, cumpre resgatar o SUS que deve ser entendido, primeiramente, enquanto política de Estado construída pelas 
forças sociais que lutaram pela democracia e se organizaram no movimento pela Reforma Sanitária Brasileira, desencadeando diversos processos de mudanças no âmbito jurídico, político, institucional, organizativo e operacional do sistema de saúde ${ }^{(23-24)}$, tal qual é reconhecido por autoridades internacionais como o maior e mais eficiente sistema de saúde universal(23-24). Estudo recente avaliando os 30 anos da existência do SUS, foram destacadas as contribuições significativas no acesso aos serviços de saúde, o que resultou em reduções das desigualdades sociais e melhoria da equidade. ${ }^{(24)}$

Entretanto, o SUS se apresenta em uma arena permanente de conflitos, negociações, pactos, com os quais se tenta, na maioria das vezes, administrar crises e introduzir reformas em aspectos parciais de sua estrutura organizacional e político gerencial ${ }^{(23)}$. Ademais, a agenda neoliberal instalada no país, especialmente, com as medidas de austeridade fiscais implementadas em 2016 - Emenda Constitucional 95 (EC-95), associadas às novas políticas ambientais, educacionais e de saúde do atual governo brasileiro, tem ameaçado a sustentabilidade e capacidade do sistema de ofertar acesso universal ${ }^{(24)}$. Nesse sentido, o Conselho Nacional de Saúde (CNS) vem intensificando sua campanha pela revogação da referida EC-95. No fim de 2019, o prejuízo ao SUS já era de R\$20 bilhões com a EC-95, antes da pandemia de COVID-19 $9^{(25)}$. Ao longo de duas décadas, os danos são estimados em R $\$ 400$ bilhões - montante a menos para custear o SUS ${ }^{(25)}$, o que tem causado um sucateamento paulatino em vários pontos $\mathrm{da}$ Rede de Atenção à Saúde (RAS).

Um outro desafio a ser transposto pelo SUS diante da pandemia se refere ao número de leitos para o tratamento intensivo dos casos críticos da COVID-19. Estimativas apontaram que em $72 \%$ das regiões de saúde do país, o número de leitos de UTI por $100 \mathrm{mil}$ habitantes é inferior ao mínimo neces- sário, mesmo para um ano típico, sem considerar as necessidades colocadas pela COVID-19 ${ }^{(26)}$. No país existe uma razão 15,6 leitos de Unidade de Terapia Intensiva (UTI) por 100.000 habitantes, sendo a média no SUS de 7,1 por 100 mil habitantes. Em um cenário de $20 \%$ da população infectada, e 5\% dos infectados necessitando cuidados em UTI por 5 dias, 294 das 436 regiões de saúde do país ultrapassariam a taxa de ocupação de $100 \%{ }^{(26)}$.

Já havia sido previsto em coletiva à imprensa sobre a COVID-19, em 20 de março de 2020, na ocasião, o então Ministro da Saúde Luiz Henrique Mandetta e sua equipe técnica já projetava que o SUS entraria em "colapso" no final do mês de abril, como ocorreu em diversos outros países; e ratificou a necessidade de seguir as recomendações de mitigação da propagação do vírus, especialmente, com relação ao isolamento social. Porém, contrariamente às orientações do Ministério da Saúde, em 24 de março de 2020 houve um pronunciamento em cadeia nacional de rádio e TV onde o presidente Jair Bolsonaro pediu a reabertura do comércio e das escolas e o fim do "confinamento em massa", o que contraria todas as recomendações de experts e de agências nacionais e internacionais de saúde pública sobre as medidas adotadas no combate ao SARS-CoV2 $2^{(27)}$. Tal postura do presidente tem sido alvo de críticas pela comunidade científica de todo o mundo, agências de saúde, e pela mídia nacional e internacional ${ }^{(27)}$.

O Diretor-Geral da OMS, Tedros Adhanom Gheybresus em 30 de março de 2020 em pronunciamento, voltou a pedir por políticas públicas para trabalhadores informais - os mais afetados em meio à crise econômica desencadeada no contexto da pandemia pela COVID-19. Acrescentou ainda que, as açóes governamentais precisam considerar as pessoas mais vulneráveis ${ }^{(28)}$. Em novo pronunciamento em 31 de março de 2020 em rede nacional de rádio e TV, o presidente Jair Bolsonaro se aproveitou do tema para embasar o discurso de normaliza- ção das atividades econômicas. Segundo Bolsonaro, Tedros falou "praticamente" que os informais "têm que trabalhar" durante a crise causada pela COVID-19. No entanto, o presidente não contextualizou a fala de Gheybresus e omitiu o recado dado aos governantes de que cabe a eles auxiliar com a promoção de políticas públicas, políticas sociais. Após muita pressão, o presidente Jair Bolsonaro sancionou com vetos a Lei $\mathrm{n}^{\circ} 13.982 \mathrm{em}$ 2 de abril de 2020, que estabeleceu um auxílio de $\mathrm{R} \$ 600$ mensais, por três meses, a trabalhadores informais. O auxílio tem o objetivo de diminuir o impacto da pandemia do coronavírus na renda dessas pessoas - que não têm carteira assinada e, por isso, foram mais afetadas pelas medidas de isolamento social. Segundo o texto aprovado no Congresso, o trabalhador precisa ter mais de 18 anos, cumprir critérios de renda familiar e não pode receber benefícios previdenciários, seguro desemprego nem participar de programas de transferência de renda do governo federal, com exceção do Bolsa Família ${ }^{(29)}$.

\section{CONCLUSÃO}

Espera-se que a pandemia da COVID-19 sirva de exemplo para a repolitização da sociedade em defesa do SUS enquanto Sistema Universal de Saúde e não Cobertura Universal de Saúde. A Saúde Coletiva apresenta-se como campo aberto a novos paradigmas em uma luta contra-hegemônica a favor da emancipação, particularmente, no contexto sanitário atual do Brasil. Ressalta-se que, nesse contexto de pandemia, as perspectivas de consolidação do SUS, passa pelo fortalecimento da consciência de cidadania e responsabilidade social, pelo aumento da mobilização dos movimentos e organizações sociais em defesa do direito à saúde, pela conquista da adesão da maioria dos profissionais de saúde ao ideário de SUS e pelo maior comprometimento do Estado e dos dirigentes públicos do setor com a efetivação dos seus princípios e diretrizes. 
1. Zhu N, Zhang D, Wang W, Xingwang Li, Yang B, Song J, et al. A novel Coronavirus from patients with pneumonia in China, 2019. N Eng J Med 2020;382(8):727-733.

2. Cui J, Li F, Shi ZL. Origin and evolution of pathogenic coronaviruses. Nat Rev Microbiol 2019;17:181-92.

3. Huang C, Wang Y, Li X, Ren L, Zhao J, Hu Y, et al. Clinical features of patients infected with 2019 novel coronavirus in Wuhan, China. Lancet. 2020;pii:S0140-6736(20)30183-5.

4. Li R, Pei S, Chen B, Song Y, Zhang T, Yang W, Shaman J. Substantial undocumented infection facilitates the rapid dissemination of novel coronavirus (SARS-CoV2). Science 2020;pii:eabb3221.

5. Roser M, Ritchie H, Ortiz-Ospina E. Coronavirus Disease (COVID-19) - Statistics and Research. Our World in Data. https:// ourworldindata.org/coronavirus

6. Brasil. Presidência da República. Casa Civil. Decreto no 10.211, de 30 de janeiro de 2020. Dispõe sobre o Grupo Executivo Interministerial de Emergência em Saúde Pública de Importância Nacional e Internacional - GEI-ESPII [Internet]. Diário Oficial da União, Brasília (DF), 2020 jan 30 [citado 2020 mar 4];Seção 1Extra; 1.

7. Croda JHR, Garcia LP. Resposta imediata da Vigilância em Saúde à epidemia da COVID-19. Epidemiol Serv Saúde 2020;29(1):e2020002.

8. Mahase E. Covid-19: WHO declares pandemic because of "alarming levels" of spread, severity, and inaction. BMJ 2020;368:m1036.

9. Wang C, Horby, PW, Hayden FG, Gao GF. A novel coronavirus outbreak of global health concern. Lancet 2020;395:470-473.

10. Lana RM, Coelho FC, Gomes MFDC, Cruz OG, Bastos LS, Villela DAM, Codeço CT. The novel coronavirus (SARS-CoV-2) emergency and the role of timely and effective national health surveillance. Cad Saude Publica 2020;36(3):e00019620.

11. Silva Junior FJGD, Sales JCES, Monteiro CFS, et al. Impact of COVID-19 pandemic on mental health of young people and adults: a systematic review protocol of observational studies. BMJ Open. 2020;10(7):e039426.

12. Bolina AF, Bomfim E, Lopes-Júnior LC. Frontline Nursing care: the COVID-19 pandemic and the Brazilian Health System. SAGE Open Nursing. 2020. In press.

13. Lopes-Júnior LC, Bomfim E, Silveira DSC, Pessanha RM, Schuab SIPC, Lima RAG. Effectiveness of mass testing for control of COVID-19: a systematic review protocol. BMJ Open. 10:2020. In press.

14. Vosgerau DSAR, Romanowski JP. Estudos de revisão: implicações conceituais e metodológicas. Rev Diálogo Educ. 2014;14(41):165-189,

15. Cervo A, Bervian PA. Metodologia científica. 5ed. São Paulo: Prentice Hall, 2002.

16. Souza RA. The foundations of pedagogy by John Dewey: a re- flection on pragmatist epistemology. Rev Contraponto Eletrônica. 2012;12(2):227-233.

17. Donnangelo, MCF. A pesquisa em Saúde Coletiva no Brasil - a década de 70. In: ABRASCO (ed.) Ensino da Saúde Pública, Medicina Preventiva e Social no Brasil. Rio de Janeiro: Núcleo de Tecnologia Educacional para a Saúde, UFRJ. Centro Latino-Americano de Tecnologia Educacional para a Saúde (OPAS). Escola Nacional de Saúde Pública: Fiocruz, 1983; 19-35.

18. Bourdieu P. O campo científico. In: ORTIZ, R. (Org.). Pierre Bourdieu: Sociologia. São Paulo: Ática, 1983.

19. Paim JS. Desafios para a Saúde Coletiva no século XXI. Salvador: EDUFBA, 2006.

20. Schraiber LB. Prefácio Saúde Coletiva: um campo vivo. Salvador, Rio de Janeiro: EDUFBA-Editora FioCruz, 2008:9-20.

21. Coelho FC, Codeço CT. Precision epidemiology of arboviral diseases. J Public Health Emerg 2019;3:1.

22. Campos GWS. Reforma política e sanitária: a sustentabilidade do sus em questão? Cienc Saude Col 2007;12(2):301-306.

23. Paim J, Travassos C, Almeida C, Bahia L, Macinko J. The Brazilian health system: history, advances, and challenges. Lancet 2011;377(9779):1778-97.

24. Castro MC, Massuda A, Almeida G, Menezes-Filho NA, Andrade $M V$, et al. Brazil's unified health system: the first 30 years and prospects for the future. Lancet 2019;394(10195):345-356.

25. Conselho Nacional de Saúde. Ministério da Saúde. Mais SUS menos Coronavirus: CNS intensifica campanha pela revogação da EC 95/2016. http://conselho.saude.gov.br/ultimas-noticias-cns/1068-maissusmenoscoronavirus-cns-intensifica-campanha-pela-revogacao-da-ec-95-2016

26. Rache B, Rocha R, Nunes L, Spinola P, Malik AM, Massudal A. Necessidades de Infraestrutura do SUS em Preparo à COVID-19: Leitos de UTI, Respiradores e Ocupação Hospitalar. Nota Técnica n 3. IEPS: São Paulo. https://ieps.org.br/pesquisas/necessidades-de-infraestrutura-do-sus-em-preparo-ao-covid-19leitos-de-uti-respiradores-e-ocupacao-hospitalar/

27. The Lancet. COVID-19: learning from experience. Lancet 2020;395:1011.

28. World Health Organization. WHO Director-Generals remarks for G20 trade ministers. March 2020. Available in: https:// www.who.int/dg/speeches/detail/who-director-generals-remarks-for-g20-trade-ministers

29. Brasil. Lei $n^{\circ} 13.982$, de 2 de abril de 2020. Altera a Lei $n^{\circ}$ 8.742, de 7 de dezembro de 1993, para dispor sobre parâmetros adicionais de caracterização da situação de vulnerabilidade social para fins de elegibilidade ao benefício de prestação continuada (BPC), e estabelece medidas excepcionais de proteção social a serem adotadas durante o período de enfrentamento da emergência de saúde pública de importância internacional decorrente do coronavírus (Covid-19) responsável pelo surto de 2019, a que se refere a Lei $n^{\circ}$ 13.979, de 6 de fevereiro de 2020. Diário Oficial da União. Brasília: DF, 2020. 